\title{
Prediction of Surface Roughness based on the Machining Conditions with the Effect of Machining Stability
}

\author{
Yung-Chih Lin ${ }^{1,2}$, You-Chen Chen ${ }^{1}$, Kung-Da Wu' ${ }^{1}$, Jui-Pin Hung ${ }^{1 *}$ \\ 1 Graduate Institute of Precision Manufacturing Technology, National Chin-Yi University of Technology, \\ Taichung 41170, Taiwan \\ 2 Intelligent Machinery Technology Center, Industry Technology Research Institute, Central Region Campus, \\ Taichung 54041, Taiwan \\ * Corresponding author's e-mail: hungjp@ncut.edu.tw
}

\begin{abstract}
This study was aimed at analyzing the influence of the cutting parameters (spindle speed, feed rate and cutting depth) on the surface roughness of the machined parts with the influence of the machining stability of the cutter. In order to consider the chattering effect, the machining stabilities were calculated based on the measured tool tip frequency response functions. A series of machining tests were conducted on aluminum workpieces under different cutting parameters. Then, the surface roughness prediction models in the form of nonlinear quadratic and power-law functions were established based on the multivariable regression method, in which the input parameters, cutting depth and spindle speed, were respectively defined in the stable and unstable regions, according to the stability lobes diagram. The current results show that both models built with the cutting parameters defined in stable regions demonstrate higher prediction accuracy of the surface roughness, about $90 \%$, when compared with the models defined in full regions with the accuracy of about $80 \%$. In particular, the power-law model is proven to have $90 \%$ prediction accuracy when validated with the cutting parameters in a stable region. As a conclusion, the mathematical models based on the cutting parameters with well-defined machining stability were proven to show more accurate prediction ability of the surface roughness. It could be expected that the prediction model can further be applied to optimize the machining conditions in low speed roughing and high speed finishing process with desirable surface quality.
\end{abstract}

Keywords: machining conditions, machining stability, regression analysis, surface roughness

\section{INTRODUCTION}

High speed and high precision machining technology has attracted more attention in manufacturing industry due to the capability in increasing productivity with improved surface quality. Basically, the surface roughness is regarded as the important characteristics of the product quality of high precision components. In turn, the surface quality of the machined parts could be affected by various machining conditions such as cutting parameters (spindle speed, feed rate, and cutting depth), tool geometry and flank wear, cooling conditions and spindle tool vibration $[1,2]$. Generally, selection of the machining conditions is an important prerequisite to achieve the desired surface finish. A traditional method based on operators' experiences or documented references in selecting the machining conditions may lower productivity and produce unexpected quality. Therefore, the investigations on the influence of machining conditions on surface roughness have been widely conducted through experimental approaches and hence the surface qualities under different conditions were predicted [3-7].

For the development of the prediction model of surface roughness, the response surface method was mostly employed to examine the correlation between the output variable and the input variables; moreover, mathematical models were 
created based on the multivariable regression analysis [8-13]. For example, Wang and Chang [3] investigated the influence of cutting condition, tool geometry and dynamics on the surface roughness in end milling operation. They also proposed the surface roughness prediction models for both dry cutting and coolant conditions by using the surface response method. In identification of the contribution of the individual cutting parameters, Fuh and $\mathrm{Wu}$ [7] showed that the interaction between the cutting speed and the flank width has significant effects on the residual stresses and the surface roughness is greatly affected by the tool nose radius and feed. The studies of Ramesh et al. [8] and Premnath et al. [9] also showed that the interaction of the cutting speed and the feed rate had a greater influence on the surface roughness when compared to other interactions. Yalcin et al. [10] demonstrated that the surface roughness is affected by the cooling and lubrication conditions in milling, and found that the end milling under air cooling produced lower surface roughness than under the dry milling, but higher than under fluid cooling end milling. Furthermore, minimization of the surface roughness can be obtained by finding the optimal machining conditions from the mathematical model. With this approach, Routara et al. [11] found that all the three cutting parameters (spindle speed, depth of cut and feed rate) and their interactions have a significant effect on roughness. The surface response model also shows a significant dependence on the tool and workpiece material combination. Yang et al. [12] also proposed the optimization process of the machining conditions to ensure a desirable surface roughness based on the surface response methodology. The experimental results of Joshua et al. [13] reported that the machining under minimum quantity lubrication environment reduced the surface roughness value to about $20 \%$. They further addressed that the feed rates have the most significant effect on the surface roughness, followed by the spindle speed; while the depth of cut has the least effect on the surface roughness.

On the other hand, occurrence of chatter is one of the most significant limitations in increasing the metal removal rate in milling. Machining chatter is considered as a self-excited regenerative vibration during the chip generation process, which not only damaged the machined surface, but also increased the tool wear rate [14-17]. Reducing the chatter vibrations was believed to improve the surface quality of milling components [15].
Bhogal et al. [15] experimentally showed that the cutting speed is the major factor affecting the tool vibration and hence the poor surface finish. Amin et al. [16] showed the effect of chatter amplitude on the surface roughness under various cutting conditions with different tool holder through machining experiments. Babu et al. [17] proposed a multi-response optimization technique to find out the optimum cutting parameters for lesser surface roughness and amplitude of cutter vibration. In addition, Altintas et al. [18] presented an analytical form of the stability lobe theory for milling, which effectively help to select the appropriate cutting parameters of the spindle speed and axial depth to avoid chatter in the machining processes and improve the material remove rate. However, the chatter-free axial depth of cut cannot guarantee the maximum material removal rate or produce better surface quality. In this respect, Cao, et al. [19] proposed a cutting parameter selection method from the perspective of the machining stability, in which the material remove rate was an objective function and the lower bound of chatter stability lobe diagram and surface finish were taken as constraints. Their results reported an increase in the machining efficiency by about $133 \%$, according to the proposed optimization method. Tsai et al. [20] also developed a chatter identification method to identify the maximum stability limit and hence increased the material remove rate.

As mentioned previously, the roughness of a machined surface can be affected to different extent, depending on the cutting parameters selected for a specific tool and part material. A variety of prediction models of surface roughness have been widely developed based on different approaches [21-24]. However, most of models were developed with the experiments that were conducted under the machining conditions defined in specific and narrow ranges, without considering the effect of chattering on the machining quality. This study was aimed at developing a mathematical model for predicting the surface roughness in machining with chatter-free cutting condition. Considering the chattering effect, the machining stability of a specific cutter was first evaluated from the measured frequency response functions. Then, the machining experiments using aluminum alloy were conducted under various combinations of cutting conditions. The surface roughness of the machined parts was examined by means of the white light interferometer. 
Multivariable linear regression analysis was employed to determine the correlation between the surface roughness and the machining parameters. Different mathematical models are proposed for comparing the effectiveness in roughness predictions. The models are expected to be applied for improving the machining quality with a desired productivity.

\section{THEORETICAL BACKGROUND}

\section{Machining stability}

The machining stability has been widely used to assess the machining performance of the milling machines [25-27] because it can illustrate the interaction of the dynamic behavior of the spindle tool and the machining process of the cutting to different materials. In general, the machining stability of the milling machine was predicted based on the analytical model developed in study [18], which can be expressed in terms of the relationship between chatter-free axial cutting depths $\left(Z_{\text {min }}\right)$ and the spindle speed $(n)$ in end-mill operation, as follows.

In this approach, the transfer function $H(j w)=R_{e}(w)+j I_{m}(w)$ is the displacement at the tool tip responding to the dynamic cutting force, where $R_{e}$ and $I_{m}$ is the real and imaginary part of the transfer function of the spindle tool tip. The limit cutting depth $Z_{\text {min }}$ for stable machining at spindle speed $\mathrm{n}$ is defined as

$$
\begin{gathered}
Z_{\text {min }}=\frac{-1}{N K_{t} K_{r} R_{e}(\omega)} \\
n=\frac{60 \omega_{c}}{N(2 k \pi+\varphi)}, \\
\varphi=\pi-2 \tan ^{-1}\left(I_{m} / R_{e}\right) \quad k=\operatorname{lobes}(0,1,2 \ldots)
\end{gathered}
$$

In the equation above, $K_{t}$ and $K_{r}$ are cutting resistance coefficients in the tangential and radial directions to the cutter. $N$ is the number of cutter teeth and $k$ is the lobe number.

\section{Multivariable regression analysis}

Generally, the mathematical model of surface roughness can be practically established based on the cutting parameters of the machining system by means of the different methods, including the statistics model, exponential function, and multivariable regression analysis. Basically, the relationship between the cutting conditions and the surface roughness can be characterized by the general form

$$
Y=\phi\left(\varepsilon, X_{1}, X_{2}, \ldots \ldots X_{n}\right)
$$

where $Y$ is the desired model of surface roughness and

$\varphi$ is the surface response function to be determined by the cutting parameters $X_{i}$.

In this study, the multiple linear regression analysis was performed to find out the surface response function, which is defined as a linear combination of several independent variables and one dependent variable in the form:

$$
Y=\beta_{0}+\beta_{1} X_{1}+\beta_{2} X_{2}+\ldots \ldots \ldots \ldots \ldots+\beta_{k} X_{k}+\varepsilon
$$

where $\beta_{i}, i=0,1,2, \ldots$ is the regression coefficient,

$\varepsilon$ is the total truncation errors. This system can also be written in matrix form:

$$
\begin{aligned}
& {[\mathrm{Y}]=[\mathrm{X}][\beta]+[\varepsilon]} \\
& \mathrm{y}=\beta_{0}+\sum_{\mathrm{j}=1}^{\mathrm{k}} \beta_{\mathrm{j}} \mathrm{X}_{\mathrm{ij}}+\varepsilon_{\mathrm{i}}
\end{aligned}
$$

The regression coefficients can be obtained by using the well known least-squares method.

\section{Mathematical model}

The mathematical function of surface roughness $\left(R_{\alpha}\right)$ is proposed to be related the cutting depth $(Z)$, spindle speed $(S)$ and feed rate $(F)$ by nonlinear model in the form as below:

1. Nonlinear polynomial model

$$
\begin{gathered}
R_{a}=\beta_{0}+\beta_{1} Z+\beta_{2} S+\beta_{3} F+ \\
+\beta_{4} \cdot Z \cdot S+\beta_{5} \cdot S \cdot F+\beta_{6} \cdot Z \cdot F+\beta_{7} \cdot Z \cdot F \cdot S
\end{gathered}
$$

2. Nonlinear power-law model

$$
R_{a}=C \cdot Z^{\beta 1} \cdot S^{\beta 2} \cdot F^{\beta 3}
$$

This model can be expressed in logarithmic transformation form, as follows

$$
\ln R_{a}=\ln C+\beta_{1} \cdot \ln Z+\beta_{2} \cdot \ln S+\beta_{3} \cdot \ln F
$$

In the models above, the regression coefficients $\beta_{i}(i=0,1,2)$ are to be estimated from the experimental data with the method of least squares regression analysis. 


\section{EXPERIMENT APPROACHES}

Basically, the prediction model of the surface roughness can be established based on the experimentally data driven approach and regression analysis. The training data including the cutting parameters and measured roughness of the machined parts were obtained from the machining tests. The main procedures were briefly addressed.

1) Conduct impact test on spindle tool with 4-flute carbide cutter to obtain the frequency response functions (FRFs) of the cutter (Figure 1 and 2)

2) Calculate the stability lobes diagram (Figure 3).

3) Perform machining tests under different machining conditions, cutting depth $=1-4 \mathrm{~mm}$, spindle speed $=3000-10000 \mathrm{rpm}$ (Figure 4$)$

4) Examine the surface roughness of the machined parts by light interferometers (Figure 5)

5) Validate the stability lobes by identification of the occurrences of machining chattering.

6) Data analysis, perform the regression analysis to examine the correlation between surface roughness and cutting parameters.

\section{Vibration Tests}

For defining the machining stability of a specific cutter, the authors first performed the vibration test on the milling machine to assess the frequency response of the tool tip. The experimental configuration is shown in Figure 1, in which a BT tool holder with 4-flute carbide cutter of $10 \mathrm{~mm}$ in diameter is installed in the spindle. In the test, the spindle head was located at a height of $200 \mathrm{~mm}$ from the working table. The hammer was applied to hit the tool end to excite the vibration of spindle tool system. An accelerometer was mounted on the tool end at the opposite side to assess the frequency response of the spindle tool. The frequency response at the spindle nose without tool holder was measured in the similar way.

\section{Frequency response function and machining stability}

Figure 2 shows the frequency response functions measured at the spindle nose and tool tip, respectively, which are presented in terms of the tool compliance and real part as a function of the excited frequency. As shown in Figure (2a), the spindle without a tool holder shows a peak amplitude of about $0.06 \mu \mathrm{m} / \mathrm{N}$, at the resonant frequency of $420 \mathrm{~Hz}$, which is mainly associated with the vibration mode of the spindle in the head stock. Besides, it is found in Figure 2(b) that the milling tool shows the maximum compliance of $1.42 \mu \mathrm{m} / \mathrm{N}$ at the frequency of $920 \mathrm{~Hz}$, which is regarded as the dominant mode of the machining stability of the milling machine.

For the calculation of machining stability, stock material of A17075 was used for machining. The cutting resistance coefficients were calibrated as $\mathrm{Kt}=796 \mathrm{~N} / \mathrm{mm}^{2}$ and $\mathrm{Kr}=0.21$ [18]. Following the equations in section 2.1, the stability lobes of the cutter were caculated and illustrated in Figure 3. In the figure, the cutting with chatter or no chatter can be defined from lobes boundary. For example, for a cutting of axial depth of $2 \mathrm{~mm}$, chattering can be expected to occur in machining under spindle speeds of 4000 or 5400 or $7376 \mathrm{rpm}$, but no chatter occurrs when the spindle speed is increased to $8000 \mathrm{rpm}$. As observed in Figure 3, the limited axial cutting depth is about $2.5 \mathrm{~mm}$, which means that a stable machining without chatter can be obtained when the cutting under axial depth of $2.5 \mathrm{~mm}$ is adopted.
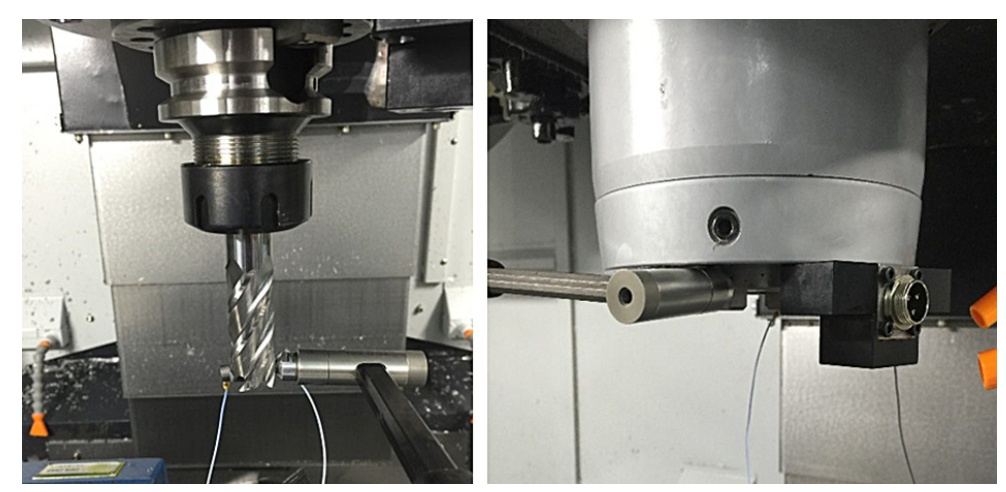

Fig. 1. Experimental configurations of vibration test of milling spindle with and without tool holder/cutter: (a) measurement at tool tip; (b) measurement at spindle nose 

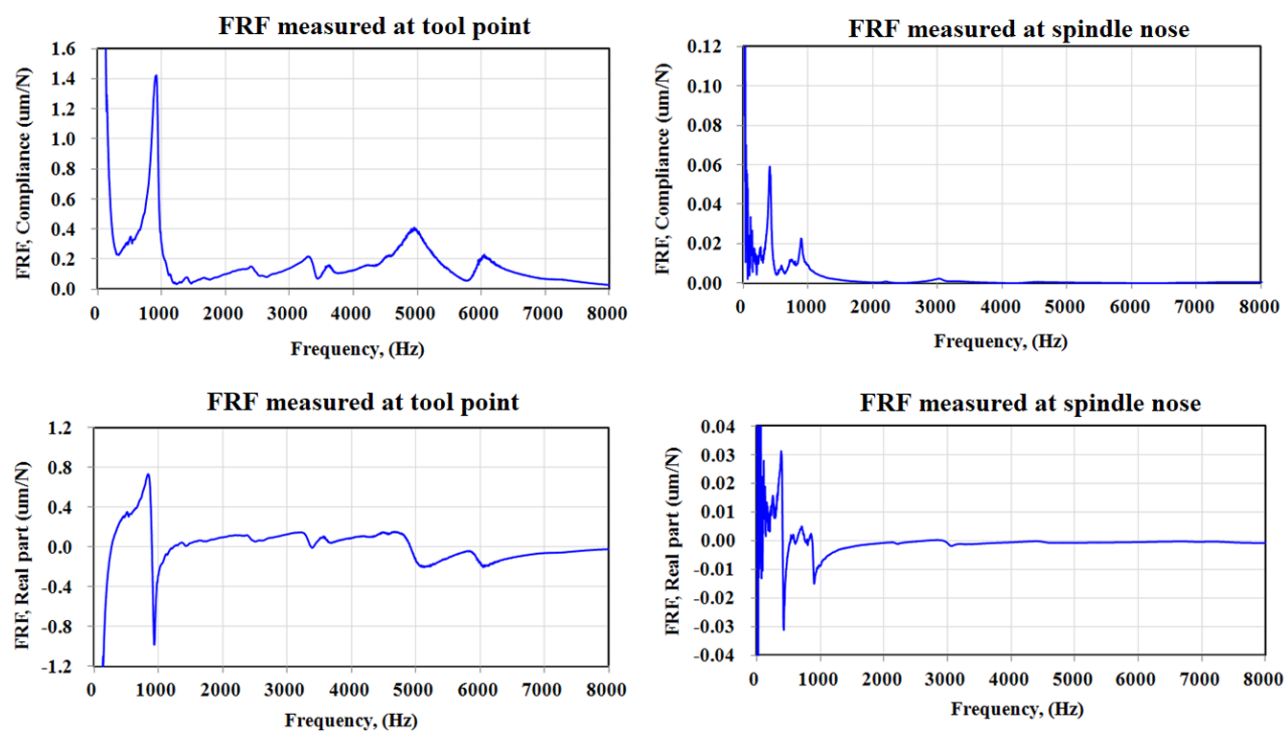

Fig. 2. Frequency response function of the spindle tool

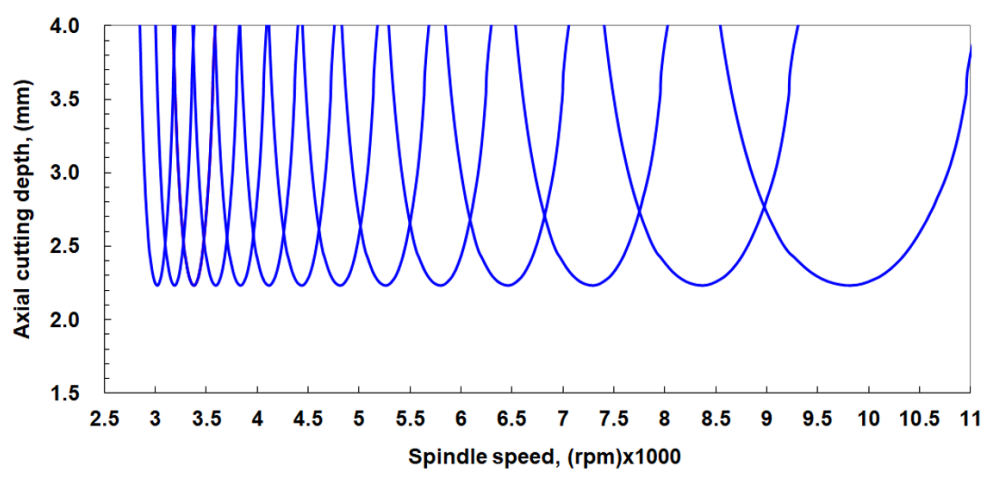

Fig. 3. Stability lobes diagram in $\mathrm{X}$ direction

\section{Machining tests}

In order to validate the stability lobes, a series of machining tests were performed by full immersion of slot milling, as shown in Figure 4. Each slot was milled at specific axial depth and spindle speed in the X-direction at specific feeding rate. The axial cutting depth was set from 1.0 to $4.0 \mathrm{~mm}$ with increment of $0.5 \mathrm{~mm}$, which includes the milling processes from the stable to unstable zones. The spindle speed was set in the range from 3000 to $10000 \mathrm{rpm}$, increased by $500 \mathrm{rpm}$, and the feed rate was set at $0.05,0.075$ and $0.1 \mathrm{~mm}$ per flute. In the tests, an accelerometer was mounted on the spindle housing to measure the vibration of the milling tool. After the tests, the surface roughness of each machined slot was measured by using the white light interferometer (Optical Surface Profiler, Zygo, NewView ${ }^{\mathrm{TM}}$ 8000 Series). The machining chatter was identified through a visual examination on the measured morphologies of the machined surfaces.
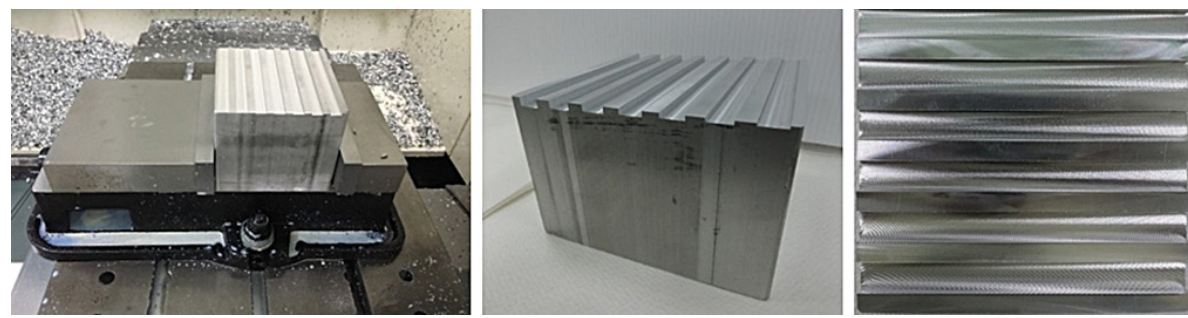

Fig. 4. Machining test and workpiece 


\section{Measurements of the machined surfaces and vibration spectrum}

Figure 5 shows the morphologies of the machined surfaces and the vibration spectrum of the milling spindle under different cutting depth and spindle speed, which indicate that the cutting with greater vibration level has a rougher surface. For example, for the cutting with depth $2.0 \mathrm{~mm}$ at speed of $3000 \mathrm{rpm}$, the surface roughness $R a$ was measured as about $1.241 \mu \mathrm{m}$ while caused a vibration level of $2.2(\mathrm{~g})$. When the cutting depth was set at $1.0 \mathrm{~mm}$, a better surface roughness $(R a$ $1.507 \mu \mathrm{m})$ was generated under the spindle speed of $8500 \mathrm{rpm}$ with the vibration level of $4.0(\mathrm{~g})$. When the cutting depth was set at $4 \mathrm{~mm}$, chattering was observed at abnormal vibration of $15.0(\mathrm{~g})$. The surface roughness was measured as $3.145 \mu \mathrm{m}$.

\section{RESULTS AND DISCUSSIONS}

\section{Validation of the stability lobes}

In order to validate the stability diagram of the milling tool, the machining status with chatter, no chatter (unstable) or ambiguous state of each cutting process was depicted on the lobes diagrams

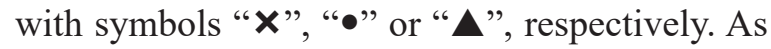
shown in Figure 6, the milling operation status agrees well with predicted stability lobes, which clearly illustrates the stability boundary of the machining conditions.

\section{Variation of surface roughnesswith different cutting parameters}

The influences of the machining parameters on the machined surface quality are demonstrated in Figure 7, which shows the distributions of the surface roughness $(R a)$ of the specimens over different cutting depth $(Z)$ and spindle speed $(S)$ of the machining under specific feed rate (F). In the case of machining test at feed rate of $0.05 \mathrm{~mm} /$ flute, better surface quality was generated with the roughness value less than $2.0 \mu \mathrm{m}$ when the spindle was operated at a speed between 4000 and $6000 \mathrm{rpm}$ and between 8000 to $10000 \mathrm{rpm}$. However, at a speed of $7000 \mathrm{rpm}$, significant variation was observed in the roughness value. Especially, when the cutting depth was higher than $2.5 \mathrm{~mm}$, the surface quality became worse (roughness value $R a>2.5 \mu \mathrm{m}$ ). This was probably caused by chatter due to the unstable cutting conditions employed in machining.

In the case of machining test at feed rate of $0.075 \mathrm{~mm} /$ flute, the surface roughness obtained was more than $2.5 \mu \mathrm{m}$ when machined at speed of $6500 \mathrm{rpm}$, irrespective of the cutting depth. For machining at feed rate of $0.1 \mathrm{~mm} /$ flute, spindle speed of 6500 and $8000 \mathrm{rpm}$ also produced worse surface quality with roughness value higher than $3.0 \mu \mathrm{m}$. In general, the surface roughness scatters in wide range, but at lower depth cutting, better surface quality can be obtained with the roughness value less than $2.0 \mu \mathrm{m}$. From the ANOVA analysis, it was found that the cutting depth and

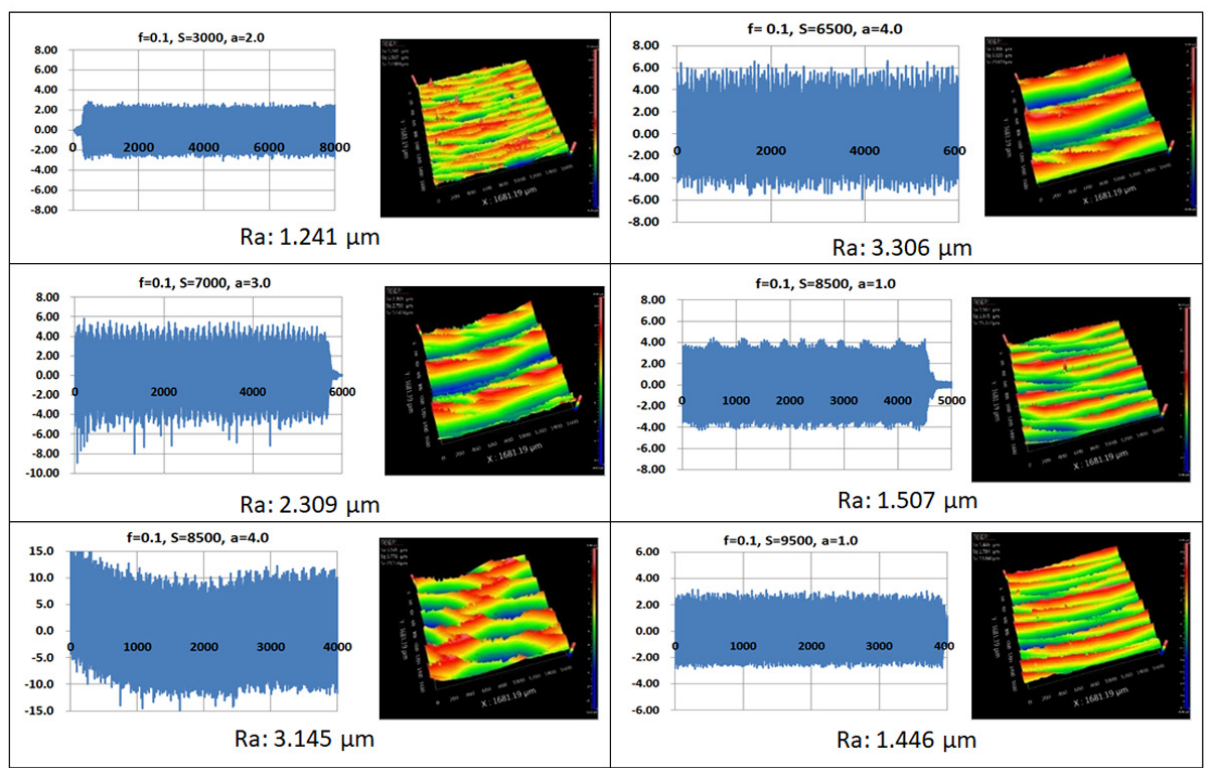

Fig. 5. Morphologies of the machined surfaces with the vibration spectrums of the spindle tool under different machining conditions 

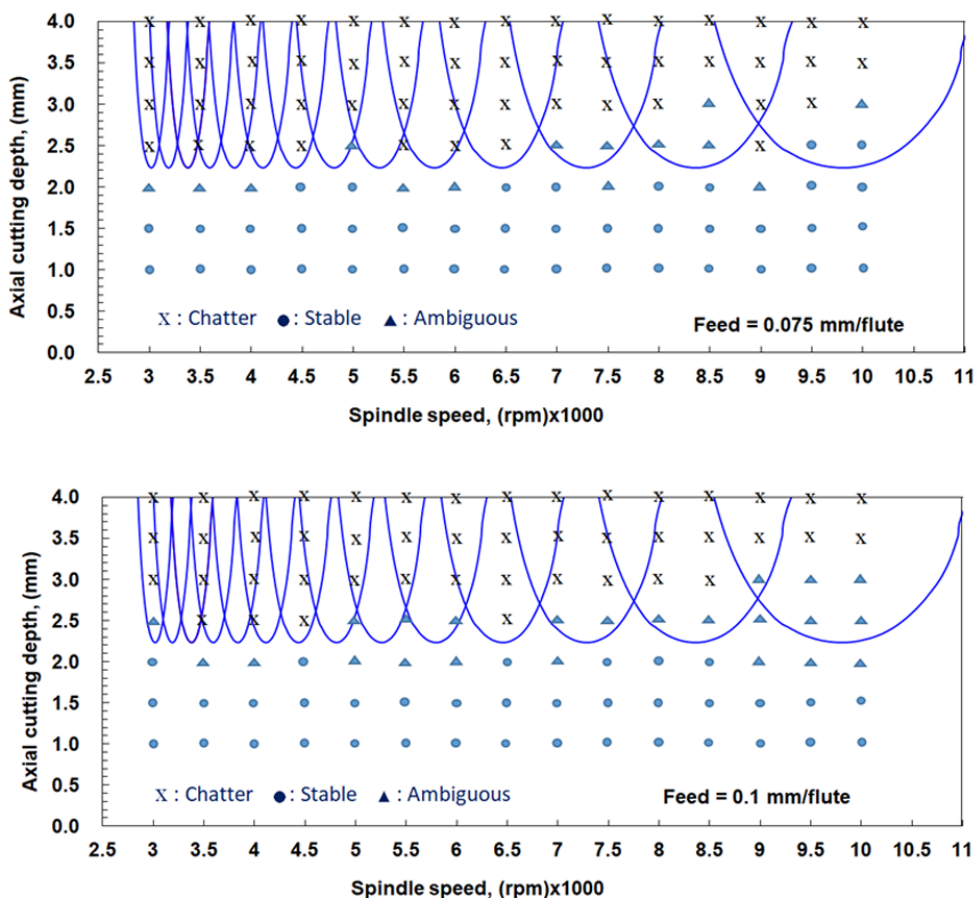

Fig. 6. Verification of the predicted stability lobes diagrams with machining tests
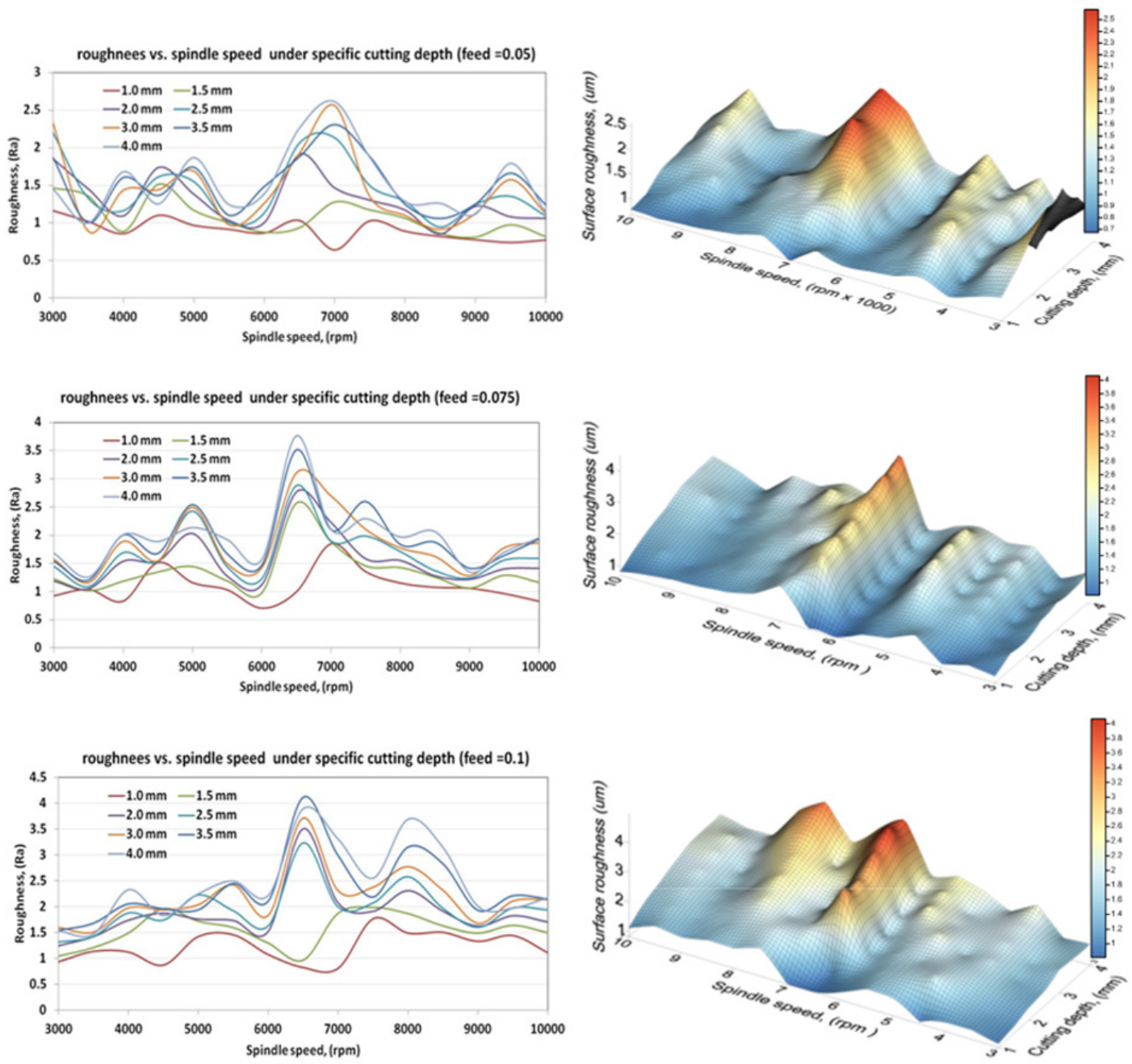

Fig. 7. Distributions of the surface roughness under different cutting depths (a) and spindle speed (s) at specific feed rate, of $0.05,0.075$ and $0.1 \mathrm{~mm} /$ flute, respectively 
feed rate, respectively, show significant influences on the surface roughness, with P-value far less than 0.001 and positive correlation coefficient $(\mathrm{R} \geq 0.97)$. Within the selected ranges of the cutting conditions, the surface roughness becomes worse when the cutting depth or feed rate is increased. However, the spindle speed has no apparent effect on the roughness value. Besides, the interactive effects between the spindle speed and the other two parameters (feed rate and cutting depth) were found to show positive influences on the surface roughness, with correlation coefficients $(\mathrm{R}>0.6)$ between roughness and product of depth, speed and feed rate.

\section{Mathematical model of surface roughness}

Multivariable regression analysis was employed to establish the mathematical model to describe the relationship between surface roughness $(R a)$ and cutting depth $(Z)$, feed rate $(F)$ and spindle speed $(S)$, as below. The spindle speed varies from 3000 to $10000 \mathrm{rpm}$, increased by $500 \mathrm{rpm}$, which is expressed as the number 1 to 10 in regression analysis. The cutting depth varies from 1.0 to $4.0 \mathrm{~mm}$, increased by $0.5 \mathrm{~mm}$ and the feed rate is $0.05,0.075$ and $0.1 \mathrm{~mm} /$ flute, respectively. The measured surface roughness of the machined samples scatters in ranges of 0.645 to $4.12 \mu \mathrm{m}$. In order to consider the interactive effects of the cutting parameters in different ways, the nonlinear quadratic and power-law models are proposed. In addition, to illustrate the influences of the machining stability of the cutter in affecting the machining quality, the regression analysis was performed using the cutting parameters defined in the (1) full region with stable and unstable conditions (training data set $=315$ ) and (2) in the regions without chattering effects (training data set $=130$, validation data set $=12$ ), as shown in Figure 6 .

\section{Cutting parameters defined in full region}

In the following regression analysis, the cutting parameters were selected within stable and unstable regions of lobes diagram. Two different models were presented for comparing the prediction accuracy.

a) Nonlinear quadratic model with coupled effects

In this case, the surface roughness $(R a)$ was determined by individual cutting parameter as well as the interactive parameters. The regression coefficients are listed in Table 1, which shows that no significant correlations between the surface roughness and the individual cutting parameter and their interactions. The mathematical model is given by

$$
\begin{gathered}
R_{a}=1.865304-0.04399 \times Z-0.18416 \times S- \\
-10.7552 \times F+0.008511 \times Z \times S+ \\
3.17376 \times Z \times F+2.084434 \times S \times F+ \\
+0.107378 \times Z \times S \times F
\end{gathered}
$$

b) Nonlinear power-law model

Table 2 shows the regression coefficients of the power-law model. It was found that the P-value of cutting depth and feed rate against surface roughness were far lesser than 0.05 , indicating the two parameters have apparent and positive influences on the roughness of the machined surface. The spindle speed also shows slight influences on the surface roughness in positive way. By using these coefficients, the roughness $(R a)$ could be expressed as

$$
R_{a}=3.9958\left(Z^{0.4348} \times S^{0.0652} \times F^{0.5453}\right)
$$

The average percentage of prediction accuracy is about 81.57 and $80.9 \%$ for the nonlinear polynomial model and power-law model, respectively. This indicates that there is no apparent difference in prediction of the surface roughness by the two models, both with an inaccuracy of $20 \%$ for all testing data.

\section{Machining parameters defined in stable regions}

In this section, a regression analysis was performed based on the cutting conditions within stable regions. The measured surface roughness of the machined samples scatters in the ranges of

Table 1. Regression parameters of the nonlinear polynomial model

\begin{tabular}{|c|c|c|c|}
\hline Parameters & Coefficients & $\begin{array}{c}\text { Standard } \\
\text { deviations }\end{array}$ & P-value \\
\hline Intercept & 1.8653 & 0.8201 & 0.0236 \\
\hline Cutting depth $(Z)$ & -0.0440 & 0.3046 & 0.8853 \\
\hline Spindle speed $(S)$ & -0.1842 & 0.1197 & 0.1250 \\
\hline Feed rate $(F)$ & -10.7552 & 10.5506 & 0.3088 \\
\hline $\begin{array}{c}\text { Depth } \times \text { speed } \\
(Z \times S)\end{array}$ & 0.0085 & 0.0445 & 0.8483 \\
\hline $\begin{array}{c}\text { Depth } \times \text { feed } \\
(Z \times F)\end{array}$ & 3.1738 & 3.9184 & 0.4186 \\
\hline $\begin{array}{c}\text { Feed } \times \text { speed } \\
(F \times S)\end{array}$ & 2.0844 & 1.5403 & 0.1770 \\
\hline $\begin{array}{c}\text { Depth } \times \text { speed } \times \\
\text { feed }(Z \times S \times F)\end{array}$ & 0.1074 & 0.5721 & 0.8512 \\
\hline
\end{tabular}


Table 2. Regression parameters of the power-law model

\begin{tabular}{|c|c|c|c|}
\hline Parameters & Coefficients & $\begin{array}{c}\text { Standard } \\
\text { deviations }\end{array}$ & P-value \\
\hline Intercept & 1.3853 & 0.1491 & $2.78 \mathrm{E}-18$ \\
\hline $\begin{array}{c}\text { Cutting depth } \\
(Z)\end{array}$ & 0.4348 & 0.0305 & $9.24 \mathrm{E}-36$ \\
\hline $\begin{array}{c}\text { Spindle speed } \\
(S)\end{array}$ & 0.0652 & 0.0384 & 0.090607 \\
\hline Feed rate $(F)$ & 0.5453 & 0.0489 & $1.85 \mathrm{E}-24$ \\
\hline
\end{tabular}

0.645 to $2.77 \mu \mathrm{m}$. Similarly to previous analysis, the spindle speed was between 3000 and $10000 \mathrm{rpm}$ and the feed rate was $0.05,0.075$ and $0.1 \mathrm{~mm} /$ flute, respectively. However, the cutting depth ranged from 1.0 to $2.5 \mathrm{~mm}$, falling in the stable region without chattering. On the basis of these coefficients, two nonlinear models were presented for comparisons.

a) Nonlinear quadratic model with coupled effects

The regression coefficients of the polynomial model are listed in Table 3. Again, no significant correlations were found between surface roughness and individual cutting parameter and their interactions. The regression model is as follows:

$$
\begin{aligned}
R_{a}= & 0.1799+1.1328 \times Z-0.0399 \times S- \\
& -1.6050 \times F-0.0882 \times Z \times S+ \\
+ & 1.5668 \times Z \times F-3.2145 \times S \times F+ \\
& +0.3714 \times Z \times S \times F
\end{aligned}
$$

\section{b) Nonlinear power-law model}

Table 4 shows the regression coefficients of the power-law model. As observed, the machining parameters, cutting depth and feed rate, showed positive influences on the surface roughness, whereas the spindle speed has a negative impact. This is a contrary tendency to the one observed in the model defined in full machining

Table 3. Regression parameters of the nonlinear polynomial model

\begin{tabular}{|c|c|c|c|}
\hline Parameters & Coefficients & $\begin{array}{c}\text { Standard } \\
\text { deviations }\end{array}$ & P-value \\
\hline Intercept & 0.1799 & 1.0778 & 0.8677 \\
\hline Cutting depth $(Z)$ & 1.1328 & 0.7045 & 0.1105 \\
\hline Spindle speed $(S)$ & -0.0399 & 0.1492 & 0.7898 \\
\hline Feed rate $(F)$ & -1.6050 & 13.1324 & 0.9029 \\
\hline Depth $\times$ speed $(Z \times S)$ & -0.0882 & 0.0972 & 0.3663 \\
\hline Depth $\times$ feed $(Z \times F)$ & 1.5668 & 1.7901 & 0.3832 \\
\hline Feed $\times$ speed $(F \times S)$ & -3.2145 & 8.3333 & 0.7004 \\
\hline $\begin{array}{c}\text { Depth } \times \text { speed } \times \\
\text { feed }(Z \times S \times F)\end{array}$ & 0.3714 & 1.1277 & 0.7425 \\
\hline
\end{tabular}

condition regions. The surface roughness $(R a)$ is related to the cutting parameters $(Z, F$ and $S)$ in the following form

$$
R_{a}=3.2047\left(Z^{0.5295} \times S^{-0.0217} \times F^{0.4121}\right)
$$

The relationship between the predicted and measured values was illustrated in Figure 8, which clearly indicates the two mathematical models were created with high prediction accuracy. The average accuracy of the surface roughness predicted by nonlinear polynominal model and power-law model is about 88.4 and $89.2 \%$, respectively.

\section{Validation of the models}

Compared with the models defined with all machining parameters, the models derived from parameters within in stable regions clearly demonstrate higher prediction accuracy of the surface roughness. Further validation of the stable prediction models was examined for the machining parameters in the experimental tests, which was excluded in the previous regression analysis for building the prediction model. The validations of the experimental data are shown in Table 5. In the case of the cutting parameters (cutting depth and spindle speed) falling in the stable region, the error between the actual value and predicted value is $10.60 \%$ for the power law model and $15.53 \%$ for the nonlinear polynomial model. This clearly confirms the power law model shows the superiority in estimating the roughness of the machined surface. However, these models likely do not perform well, with greater deviation when the cutting depth and spindle speed fall in the unstable region. The validation results reveal that the development of surface roughness prediction model is greatly dependent on the selection of the training data, which are related to the machining stability of the cutter.

Table 4. Regression parameters of the power-law model

\begin{tabular}{|c|c|c|c|}
\hline Parameters & Coefficients & $\begin{array}{c}\text { Standard } \\
\text { deviations }\end{array}$ & P-value \\
\hline Intercept & 1.1646 & 0.1949 & $2.24 \mathrm{E}-08$ \\
\hline $\begin{array}{c}\text { Cutting depth } \\
(Z)\end{array}$ & 0.5295 & 0.0535 & $2.19 \mathrm{E}-17$ \\
\hline $\begin{array}{c}\text { Spindle speed } \\
(S)\end{array}$ & -0.0217 & 0.0477 & $6.50 \mathrm{E}-01$ \\
\hline Feed rate (F) & 0.4121 & 0.0625 & $1.11 \mathrm{E}-09$ \\
\hline
\end{tabular}



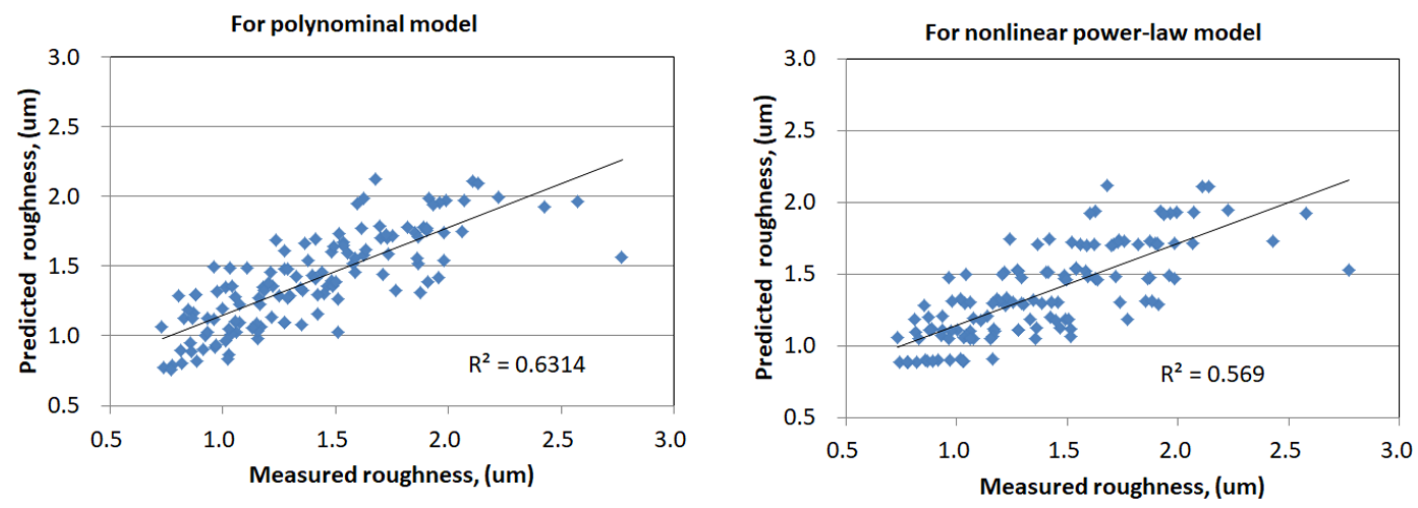

Fig. 8. Comparisons of surface roughness between the predicted and measured values.

According to the regression model in Eq. (11), the prediction model in the form of polynomial function, the cutting depth has positive effects on the surface roughness, indicating that cutting with more axial depth induces an increase in roughness. However, the feed rate affects the surface roughness in negative way, increasing the feeding rate may improve the surface finish of the machined part, while the influence of the spindle speed appears unpredictable than other parameters, because the cutting parameters selected for regression analysis scatter in wide ranges from 3000 to $10000 \mathrm{rpm}$. As observed in Figure 7, the spindle speed around
6000 to $7000 \mathrm{rpm}$ causes a poor surface precision, while the speed higher than $8000 \mathrm{rpm}$ is more favorable for better surface quality due to the increasing cutting speed.

In addition, the interactions of the cutting parameters yield different influences. For example, the interaction between the cutting depth and feed rate has significant influence on the surface roughness, indicating that increasing the cutting depth and feeding speed deteriorates the surface finish. Additionally, increasing the spindle speed can reduce the surface roughness under specific feed rate of $0.05 \mathrm{~mm} /$ flute and cutting depth of 1 and $2 \mathrm{~mm}$, as shown in

Table 5. Validations of the prediction models

\begin{tabular}{|c|c|c|c|c|c|c|c|}
\hline \multicolumn{3}{|c|}{ Cutting parameters } & \multicolumn{5}{|c|}{ Surface roughness $(\mu \mathrm{m})$} \\
\hline \multirow{2}{*}{$\begin{array}{l}\text { Cutting } \\
\text { depth } \\
(\mathrm{mm})\end{array}$} & \multirow{2}{*}{$\begin{array}{l}\text { Spindle speed } \\
\text { (rpm) }\end{array}$} & \multirow{2}{*}{$\begin{array}{l}\text { Feed rate } \\
(\mathrm{mm} / \mathrm{min})\end{array}$} & \multirow{2}{*}{$\begin{array}{l}\text { Measured } \\
\text { values }\end{array}$} & \multicolumn{4}{|c|}{ Predictions } \\
\hline & & & & \multicolumn{2}{|c|}{$\begin{array}{c}\text { Polynomial model \#1 } \\
\text { Prediction Error }\end{array}$} & \multicolumn{2}{|c|}{$\begin{array}{l}\text { Power-law model \#1 } \\
\text { Prediction Error }\end{array}$} \\
\hline 1 & 4000 & 1600 & 1.13 & 1.09 & $2.85 \%$ & 1.20 & $6.92 \%$ \\
\hline 1 & 5500 & 2200 & 1.46 & 1.19 & $18.37 \%$ & 1.20 & $18.16 \%$ \\
\hline 1.5 & 5000 & 1500 & 1.45 & 1.33 & $7.75 \%$ & 1.32 & $8.71 \%$ \\
\hline 2 & 7000 & 1400 & 1.47 & 1.34 & $8.80 \%$ & 1.29 & $12.10 \%$ \\
\hline 2 & 8000 & 1600 & 1.17 & 1.24 & $5.64 \%$ & 1.29 & $9.78 \%$ \\
\hline 2 & 9500 & 1900 & 1.08 & 1.50 & $3.47 \%$ & 1.52 & $2.09 \%$ \\
\hline 2 & 8000 & 2400 & 1.55 & 1.76 & $23.67 \%$ & 1.71 & $25.76 \%$ \\
\hline 2 & 3000 & 900 & 1.19 & 1.95 & $1.44 \%$ & 1.92 & $2.76 \%$ \\
\hline 2 & 8000 & 3200 & 2.31 & 1.74 & $12.33 \%$ & 1.71 & $13.67 \%$ \\
\hline 2.5 & 9500 & 3800 & 1.97 & 1.96 & $28.42 \%$ & 1.73 & $13.55 \%$ \\
\hline 2.5 & 7500 & 2250 & 1.99 & 2.34 & $62.69 \%$ & 1.62 & $12.82 \%$ \\
\hline \multirow[t]{2}{*}{3} & 4000 & 800 & 1.44 & 1.40 & $10.96 \%$ & 1.59 & $1.20 \%$ \\
\hline & & & & Average & $15.53 \%$ & Average & $10.60 \%$ \\
\hline \multicolumn{8}{|c|}{ Cutting depth in unstable region } \\
\hline 3 & 5500 & 1650 & 1.49 & 2.17 & $45.0 \%$ & 1.90 & $27.2 \%$ \\
\hline 3 & 8000 & 3200 & 2.77 & 2.16 & $22.0 \%$ & 2.12 & $23.5 \%$ \\
\hline 3.5 & 3000 & 600 & 1.87 & 2.89 & $54.4 \%$ & 1.77 & $5.4 \%$ \\
\hline 3.5 & 7500 & 1500 & 1.88 & 1.96 & $4.4 \%$ & 1.73 & $7.9 \%$ \\
\hline 3.5 & 5500 & 1650 & 1.67 & 2.45 & $46.7 \%$ & 2.06 & $23.6 \%$ \\
\hline 4 & 6500 & 2600 & 3.89 & 2.70 & $30.7 \%$ & 2.48 & $36.2 \%$ \\
\hline
\end{tabular}



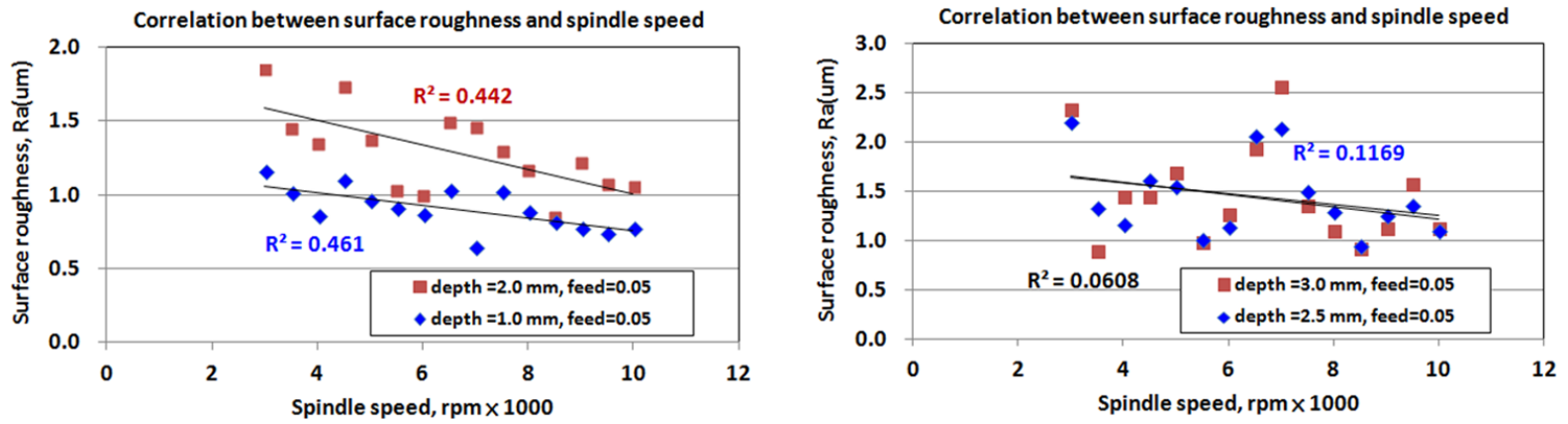

Fig. 9. Correlations between the surface roughness and the spindle speed under specific cutting conditions in the stable and unstable region

Figure 9(a). This figure clearly indicates that a higher cutting depth worsens the surface roughness as compared to the lower cutting depth. Figure 9(a) also reveals the tendency that the surface roughness can be reduced by appropriately increasing the spindle speed in machining. This is valid for the machining parameters defined in the stable regions. However, as indicated in Figure 9(b), there is no significant correlation between spindle speed and surface finish if the cutting depth is beyond the limited cutting depth of the cutter, which can be observed in the stability lobes diagram.

Similarly, as revealed in Eq. (12), the power-law model defined in the stable machining regions shows that the feed rate and cutting have negative influences on the surface precision. Increasing the spindle speed can also reduce the surface roughness or improving the surface quality. However, this effect was not observed in the power-law model defined in the full machining regions, as seen in Eq.(10), where the term, spindle speed, with positive exponents shows a positive relationship with surface roughness. This can be ascribed to the fact that some of cutting parameters in the unstable regions were also included in the regression analysis, in which the cutting depths more than the limited value are prone to induce chattering, hence generating poor surface quality. As a consequence, the mathematical models based on the cutting parameters with well-defined machining stability are proven to show more accurate prediction ability of the surface roughness. It could be expected that the prediction model can further be applied to optimize the machining conditions for the low speed roughing and high speed finishing process with a desirable surface quality.

\section{CONCLUSIONS}

This study proposed the mathematical models for the prediction of the surface roughness under various cutting conditions from low speed to high speed stable machining. Considering the effect of machining stability of the milling tool, the training data assessed from the machining tests were grouped into (1) the parameters defined in the stable and unstable regions, (2) the parameters without the chattering effects. The mathematical models were established in nonlinear polynomial function and power-law function, respectively, to relate the cutting parameters with surface roughness.

According to the analyzed results from the mathematical models defined in the full machining test range, there is no significant difference in the prediction of the surface roughness, both with about $80 \%$ prediction accuracy. However, in the case of the models built with the stable machining conditions, the average percentage of prediction accuracy of polynomial function and power-law function is about 88.4 and $89.2 \%$, respectively. The power-law model was proven to have a higher prediction accuracy, about $90 \%$ when validated with the machining conditions in a stable region. Besides, the influence of the cutting parameters along with their interaction on the surface roughness was clearly identified by using appropriate mathematical models, especially in the stable machining regions. As observed from the experimental analysis, the spindle speed was found to show a negative correlation with the surface roughness when the machining was conducted under the appropriately selected feeding rate with the cutting depth below the limited depth in the stability lobes diagram. As a final conclusion, this study demonstrated the effectiveness of the 
stability lobes in determining the machining performance and the mathematical models for an accurate prediction of the surface quality.

\section{Acknowledgments}

We gratefully acknowledge the support for this work provided by Intelligent Machinery Technology Center, Industrial Technology Research Institute, Taiwan.

\section{REFERENCES}

1. Benardos, P.G., Vosniakos, G. Predicting surface roughness in machining: a review. International Journal of Machine Tools and Manufacture. 43(8), 2003, 833-844.

2. Özel,T., Hsu, T.K., Zeren, E. Effects of cutting edge geometry, workpiece hardness, feed rate and cutting speed on surface roughness and forces in finish turning of hardened AISI H13 steel. International Journal of Advanced Manufacturing Technology. 25(3-4), 2005, 262-269.

3. Wang, M.Y., Chang, H.Y. Experimental study of surface roughness in slot end milling AL2014-T6. International Journal of Machine Tools and Manufacture. 44(1), 2004, 51-57.

4. Öktem, H., Tuncay E., Kurtaran, H. Application of response surface methodology in the optimization of cutting conditions for surface roughness. Journal of Materials Processing Technology. 170(1-2), 2005, 11-16.

5. Hayajneh, M.T., Tahat, M.S., Bluhm, J. A study of the effects of machining parameters on the surface roughness in the end-milling process. Jordan Journal of Mechanical and Industrial Engineering. 1(1), 2007, 1-5.

6. Hamdan, A., Sarhan, A.A., Hamdi, M. An optimization method of the machining parameters in high-speed machining of stainless steel using coated carbide tool for best surface finish. International Journal of Advanced Manufacturing Technology. 58(1-4), 2012, 81-91.

7. Fuh, K.H., Wu, C.F. A proposed statistical model for surface quality prediction in end-milling of $\mathrm{Al}$ alloy. International Journal of Machine Tools and Manufacture. 35, 1995, 1187-1200.

8. Ramesh, S., Karunamoorthy, L., Palanikumar, K. Measurement and analysis of surface roughness in turning of aerospace titanium alloy. Measurement. 45(5), 2012, 1266-1276.

9. Premnath, A.A., Alwarsamy, T., Abhinav, T., Krishnakant, C.A. Surface roughness prediction by response surface methodology in milling of hybrid
Aluminium composites. Procedia Engineering. 38(1), 2012, 745-752.

10. Yalçın, B., Özgür, A.E., Koru, M. The effects of various cooling strategies on surface roughness and tool wear during soft materials milling. Materials \& Design. 30(3), 2009,896-899.

11. Routara, B.C., Bandyopadhyay, A., Sahoo, P. Roughness modeling and optimization in $\mathrm{CNC}$ end milling using response surface method: effect of workpiece material variation. International Journal of Advanced Manufacturing Technology. 40(1112) , 2009, 1166-1180

12. Yang, A., Han, Y., Pan, Y., Xing, H., \& Li, J. Optimum surface roughness prediction for titanium alloy by adopting response surface methodology. Results in Physics, 7, 2017,1046-1050.

13. Joshua,O.S., David, M.O., Sikiru, I.O. Experimental investigation of cutting parameters on surface roughness prediction during end milling of aluminium 6061 under MQL (Minimum Quantity Lubrication). Journal of Mechanical Engineering and Automation. 5(1), 2015, 1-13.

14. Chiou, Y.S., Chung, E.S., Liang, S.Y. Analysis of tool wear effect on chatter stability in turning. International Journal of Mechanical Sciences. 37(4), 1995, 391-404.

15. Bhogal, S.S., Sindhu, C., Dhami, S.S., Pabla, B.S. Minimization of surface roughness and tool vibration in CNC milling operation. Journal of Optimization. ID 192030, 2015, 1-13.

16. Amin, A.N., Patwari, A.U., Sharulhazrin, M.S., Hafizuddin, I. Investigation of effect of chatter amplitude on surface roughness during end milling of medium carbon steel. Proceedings of the 2010 International Conference on Industrial Engineering and Operations Management. 2010, 131-136.

17. Babu, G.P., Murthy, B.S.N., Venkatarao, K., \& Ratnam, C. Multi-response optimization in orthogonal turn milling by analyzing tool vibration and surface roughness using response surface methodology. Proceedings of the Institution of Mechanical Engineers, Part B: Journal of Engineering Manufacture, 231(12), 2017, 2084-2093.

18. Altintas, Y., Budak, E. Analytical prediction of stability lobes in milling. CIRP Annals - Manufacturing Technology. 4(1), 1995, 357-362.

19. Cao, H., Zhou, K., Chen, X. Stability-based selection of cutting parameters to increase material removal rate in high-speed machining process. Proceedings of the Institution of Mechanical Engineers, Part B: Journal of Engineering Manufacture. 230(2), 2016, 227-240.

20. Tsai, J.C., Wang, S.J. An intelligent approach for high material removal rate machining. In Intelligent Technologies and Engineering Systems 2013, 993-999. Springer, New York, NY. 
21. Prakasvudhisarn, C., Kunnapapdeelert, S.P., Yenradee, $\mathrm{P}$. Optimal cutting condition determination for desired surface roughness in end milling. International Journal of Advanced Manufacturing Technology. 41(5-6), 2009, 440-451.

22. Okokpujie, I., Okonkwo, U., Okwudibe, C. Cutting parameters effects on surface roughness during end milling of aluminium 6061 alloy under dry machining operation. International Journal of Science and Research. 4(7), 2015, 2030-2036

23. Okokpujie, I., Ajayi, O.O., Afolalu, S.A., Abioye, A.A., Salawu, E.Y., Udo, M. Modeling and optimization of surface roughness in end milling of aluminium using least square approximation method and response surface methodology. International Journal of Mechanical Engineering and Technology. 9(1), 2018, 587-600.

24. Karunya, G., Ravikumar, P., Krishna, P.G., Krishna, P.S. Optimization of the surface roughness by ap- plying the Taguchi technique for the turning of AISI 304 austenitic stainless steel. Journal of Engineering Science and Technology. 8(8), 2017, 694-701.

25. Hung, J.P., Lai, Y.L., Luo, T.L., Su. H.C. Analysis of the machining stability of a milling machine considering the effect of machine frame structure and spindle bearings: experimental and finite element approaches. International Journal of Advanced Manufacturing Technology. 68(9-12), 2013, 2393-2405.

26. Hung, J.P., Lin, W.Z., Chen, Y.J., Luo, T.L. Investigation of the machining stability of a milling machine with hybrid guideway systems. Applied Science. 6, 2016, 76.

27. Deng, C., Miao, J., Wei, B., Feng, Y., Zhao, Y. Evaluation of machine tools with position-dependent milling stability based on Kriging model. International Journal of Machine Tools and Manufacture. 124, 2018, 33-42. 